\title{
Highly conductive grain boundaries in copper oxide thin films
}

Cite as: J. Appl. Phys. 119, 235303 (2016); https://doi.org/10.1063/1.4954002

Submitted: 23 March 2016 • Accepted: 02 June 2016 • Published Online: 16 June 2016

(D) Jonas Deuermeier, Hans F. Wardenga, Jan Morasch, et al.

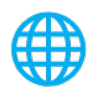

\section{ARTICLES YOU MAY BE INTERESTED IN}

Visualization of nanocrystalline $\mathrm{CuO}$ in the grain boundaries of $\mathrm{Cu}_{2} \mathrm{O}$ thin films and effect on band bending and film resistivity

APL Materials 6, 096103 (2018); https://doi.org/10.1063/1.5042046

Synthesis of $\mathrm{Cu}_{2} \mathrm{O}$ from $\mathrm{CuO}$ thin films: Optical and electrical properties

AIP Advances 5, 047143 (2015); https://doi.org/10.1063/1.4919323

Thin-film transistors based on $\mathrm{p}$-type $\mathrm{Cu}_{2} \mathrm{O}$ thin films produced at room temperature

Applied Physics Letters 96, 192102 (2010); https://doi.org/10.1063/1.3428434

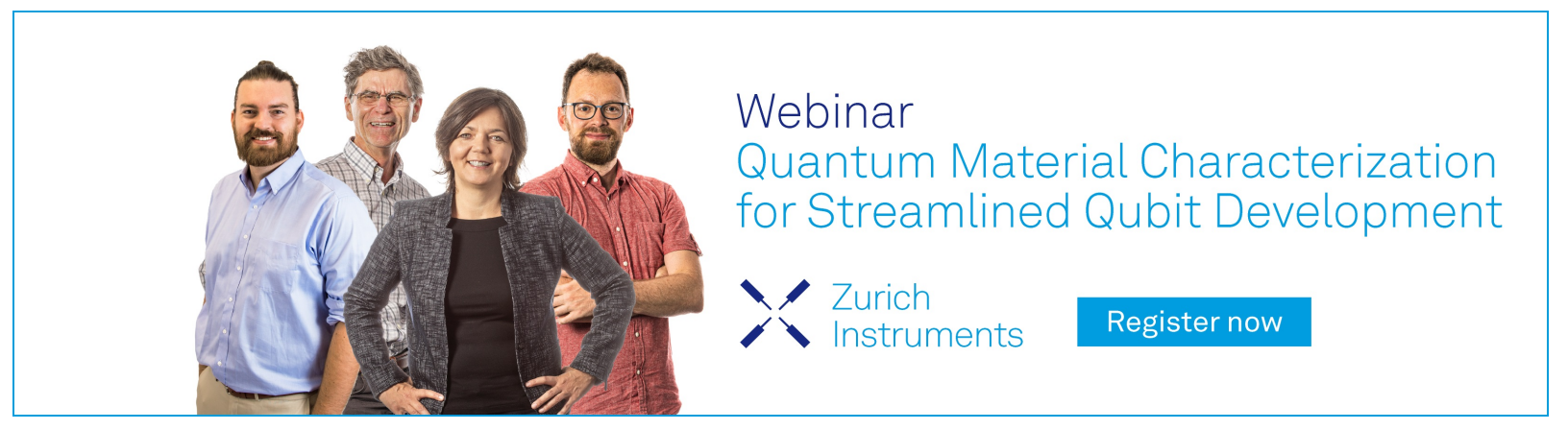




\title{
Highly conductive grain boundaries in copper oxide thin films
}

\author{
Jonas Deuermeier, ${ }^{1,2, a)}$ Hans F. Wardenga, ${ }^{2}$ Jan Morasch, ${ }^{2}$ Sebastian Siol, ${ }^{2, b)}$ \\ Suman Nandy, ${ }^{1}$ Tomás Calmeiro, ${ }^{1}$ Rodrigo Martins, ${ }^{1}$ Andreas Klein, ${ }^{2, c)}$ \\ and Elvira Fortunato ${ }^{1}$ \\ ${ }^{1}$ Department of Materials Science, Faculty of Science and Technology, i3N/CENIMAT, Universidade NOVA \\ de Lisboa and CEMOP/UNINOVA, Campus de Caparica, 2829-516 Caparica, Portugal \\ ${ }^{2}$ Department of Materials and Earth Sciences, Technische Universität Darmstadt, Jovanka-Bontschits-Straße \\ 2, D-64287 Darmstadt, Germany
}

(Received 23 March 2016; accepted 2 June 2016; published online 16 June 2016)

\begin{abstract}
High conductivity in the off-state and low field-effect mobility compared to bulk properties is widely observed in the p-type thin-film transistors of $\mathrm{Cu}_{2} \mathrm{O}$, especially when processed at moderate temperature. This work presents results from in situ conductance measurements at thicknesses from sub-nm to around $250 \mathrm{~nm}$ with parallel X-ray photoelectron spectroscopy. An enhanced conductivity at low thickness is explained by the occurrence of $\mathrm{Cu}(\mathrm{II})$, which is segregated in the grain boundary and locally causes a conductivity similar to $\mathrm{CuO}$, although the surface of the thick film has $\mathrm{Cu}_{2} \mathrm{O}$ stoichiometry. Since grains grow with an increasing film thickness, the effect of an apparent oxygen excess is most pronounced in vicinity to the substrate interface. Electrical properties of $\mathrm{Cu}_{2} \mathrm{O}$ grains are at least partially short-circuited by this effect. The study focuses on properties inherent to copper oxide, although interface effects cannot be ruled out. This non-destructive, bottom-up analysis reveals phenomena which are commonly not observable after device fabrication, but clearly dominate electrical properties of polycrystalline thin films. Published by AIP Publishing.

[http://dx.doi.org/10.1063/1.4954002]
\end{abstract}

\section{INTRODUCTION}

A significant economic potential lies within lowtemperature fabrication of transparent oxide electronics. ${ }^{1} \mathrm{~A}$ successful commercialization is primarily held back by the development of a complementary p-type transistor element. With a band gap of $2.17 \mathrm{eV},{ }^{2} \mathrm{Cu}_{2} \mathrm{O}$ is one of the candidate $\mathrm{p}$ type materials, but shows a pronounced discrepancy between bulk electrical properties and device behavior. Deposition by reactive magnetron sputtering at room temperature results in a Hall mobility of $1 \mathrm{~cm}^{2} \mathrm{~V}^{-1} \mathrm{~s}^{-1}$, however additional annealing at $200{ }^{\circ} \mathrm{C}$ for $1 \mathrm{~h}$ in air increases the mobility to $32 \mathrm{~cm}^{2}$ $\mathrm{V}^{-1} \mathrm{~s}^{-1}$ (own data, similar to results from the literature ${ }^{3,4}$ ). In contrast, bottom-gated thin-film transistors (TFTs), produced at temperatures up to $200{ }^{\circ} \mathrm{C}$, show field-effect mobilities in the order of $10^{-3} \mathrm{~cm}^{2} \mathrm{~V}^{-1} \mathrm{~s}^{-1}$. 5,6 A higher annealing temperature above $500^{\circ} \mathrm{C}$ (Refs. 7-9) is typically needed for a field-effect mobility closer to the bulk value. This is commonly related to an increased grain size. An estimation of sub-gap density of states close to the valence band maximum in a $\mathrm{Cu}_{2} \mathrm{O}$ transistor annealed at $800^{\circ} \mathrm{C}$ has resulted in a value an order of magnitude higher than that of amorphous silicon or organic TFTs. ${ }^{10}$ However, the intermediate temperature approach (below $200-300^{\circ} \mathrm{C}$ ) has been shown to be feasible by an adequate choice of bottom-gate dielectric substrate material, leading to field-effect mobilities of $2 \mathrm{~cm}^{2} \mathrm{~V}^{-1} \mathrm{~s}^{-1}$ on AlN and $0.5 \mathrm{~cm}^{2} \mathrm{~V}^{-1} \mathrm{~s}^{-1}$ on $\mathrm{SrTiO}_{3}$. ${ }^{11,12}$

Already one year after the first report on epitaxial $\mathrm{Cu}_{2} \mathrm{O}$ as active channel in a TFT, ${ }^{13}$ the interpretation of

\footnotetext{
${ }^{a}$ Electronic mail: j.deuermeier@campus.fct.unl.pt

b) Present address: National Renewable Energy Laboratory, Golden, Colorado 80401, USA

${ }^{c)}$ Electronic mail: aklein@surface.tu-darmstadt.de
}

bulk properties has led to the conclusion that the low onoff current ratio and the low field-effect mobility can be either due to a secondary phase of $\mathrm{CuO}$ or ionization of intrinsic donors (oxygen vacancy). ${ }^{14}$ In the case of highquality epitaxial films, such defects have to be localized at interfaces and/or surfaces. Apart from a well known surface oxidation of $\mathrm{Cu}(\mathrm{I})$ in $\mathrm{Cu}_{2} \mathrm{O}$ to $\mathrm{Cu}(\mathrm{II}),{ }^{15}$ a porosity of $\mathrm{Cu}_{2} \mathrm{O}$ and an interdiffused layer due to high temperature processing have been discussed to be the reasons for bad transport properties at the interface between the polycrystalline $\mathrm{Cu}_{2} \mathrm{O}$ and the dielectric substrate. ${ }^{16,17}$ In the here presented study, a surface oxidation is excluded as the electrical analysis was entirely conducted in an ultra-high vacuum (UHV).

$\mathrm{Cu}_{2} \mathrm{O}$ has been reported to exist in non-stoichiometric form, both polycrystalline and monocrystalline, when quenched from high temperatures. ${ }^{18,19}$ At room temperature and in ambient air, $\mathrm{Cu}_{2} \mathrm{O}$ is thermodynamically unstable, but the eutectoid decomposition into $\mathrm{Cu}$ and $\mathrm{CuO}$ below $375^{\circ} \mathrm{C}$ is kinetically hindered. ${ }^{20} \mathrm{~A}$ structural stabilization has been reported by (110) stacking faults in minerals of $\mathrm{Cu}_{2} \mathrm{O}$, which are understood as a missing plane of copper ions and give rise to a formal increase in copper valency of the adjacent cations. ${ }^{21}$ Grain boundaries, in general, have been shown to present regions of an increased conductivity with respect to monocrystalline material ${ }^{22}$ and act as a sink for intrinsic defects. ${ }^{23}$ Apart from segregation of intrinsic defects, inhomogeneity may also exist in the form of oxidation states different from the parent material. In $\mathrm{Cu}_{2} \mathrm{O}$, precipitate phases containing either $\mathrm{Cu}(0)$ or $\mathrm{Cu}(\mathrm{II})$ might be present. ${ }^{20} \mathrm{Cu}(0)$ is metallic and forms a Schottky barrier to $\mathrm{Cu}_{2} \mathrm{O} .{ }^{24} \mathrm{Cu}$ (II) occurs in another stable p-type oxide, $\mathrm{CuO}$, which generally exhibits a higher charge carrier concentration and lower Hall 
mobility than $\mathrm{Cu}_{2} \mathrm{O} \cdot{ }^{25-27}$ This is due to the partial $\mathrm{Cu} 3 \mathrm{~d}^{9}$ occupancy, which subjects the hole state to strong antiferromagnetic coupling. ${ }^{28}$ The higher carrier concentration is also related to the $\mathrm{Cu} 3 \mathrm{~d}^{9}$ configuration, since it introduces strong electron-electron coupling to the valence band, which shifts its maximum closer towards the Fermi energy. ${ }^{29}$ The value of the band gap is approximately $1.5 \mathrm{eV} .{ }^{30}$

In order to describe the morphology of a film grown from the vapor phase, a structure zone model has been developed. ${ }^{31}$ When grown without substrate heating, grains have fibrous structure, predominantly oriented orthogonal to the substrate surface. ${ }^{3}$ The grain size in this direction is equal to the film thickness $d$, which is related to the lateral extension of the grains $L$ according to Equation (1). ${ }^{32}$ The exponent $n$ mediates the curvature of the grain faces

$$
d \propto L^{n} .
$$

Inhomogeneous electrical properties in polycrystalline semiconductors most commonly exist in the form of poorly conductive, thin intergranular regions, with respect to the grains. Consequently, most of the literature on electrical properties of inhomogeneous semiconductors focuses on this case. ${ }^{33-35}$ A rather simple model, which accounts for highly conductive grain boundaries, has been developed for polycrystalline $\mathrm{CeO}_{2}$ on $\mathrm{SiO}_{2}$, growing with columnar morphology. In this contribution, a similar model is used to correlate thicknessdependent conductance data for $\mathrm{Cu}_{2} \mathrm{O}$ with the morphology of the material. In parallel, changes in the copper oxidation state are studied to reveal the origin of the inhomogeneous electrical properties.

\section{EXPERIMENTAL}

Sample preparation for in situ X-ray photoelectron spectroscopy (XPS) was done at the DArmstadt Integrated SYstem for MATerial research (DAISY-MAT), a cluster tool which provides UHV transfer between deposition and characterization chambers. ${ }^{36} \mathrm{Cu}_{2} \mathrm{O}$ thin films where grown by reactive radio frequency (RF) magnetron sputtering without substrate heating. A 2 in. metallic copper target of $99.999 \%$ purity purchased from Lesker was sputtered at $25 \mathrm{~W}(2.53 \mathrm{~W}$ in. ${ }^{-2}$ ) and $0.5 \mathrm{~Pa}$ total pressure. Similar to earlier studies, ${ }^{37}$ the stoichiometry of $\mathrm{Cu}_{2} \mathrm{O}$ was optimized by adjusting the gas flow ratio of oxygen with respect to the total gas flow in the range of $3.7 \%-4.3 \%$. This value had been found to depend on target consumption. Figures of merit for optimized deposition conditions were stoichiometry, obtained from areal peak intensities divided by atomic sensitivity factors provided for the instrument, ${ }^{38}$ the absence of the $\mathrm{Cu} 2 \mathrm{p}$ satellite structure of $\mathrm{Cu}(\mathrm{II}),{ }^{39}$ and a Fermi energy $E_{\mathrm{F}}-E_{\mathrm{VB}} \leq 0.3 \mathrm{eV}$. Fermi energies of $0.5-0.6 \mathrm{eV}$ were found a more sensitive indicator for small amounts of $\mathrm{Cu}(0)$ than the $\mathrm{Cu}$ LMM Auger emission. ${ }^{40} \mathrm{LMM}$ refers to the orbitals in X-ray level notations, which are involved in the Auger emission, more precisely $\mathrm{L}_{3} \mathrm{M}_{4,5} \mathrm{M}_{4,5}$. Comparatively high Fermi energies in $\mathrm{Cu}_{2} \mathrm{O}$ can be related to a depletion by the formation of Schottky barriers to nanocrystalline copper precipitates. ${ }^{41,42}$ Samples of $\mathrm{CuO}$ were grown with similar condition, but using an oxygen gas flow ratio of $10 \%$.
As substrates, $\mathrm{SiO}_{2}$ quartz glass, $\mathrm{Al}_{2} \mathrm{O}_{3}$ and $\mathrm{Bi}_{2} \mathrm{O}_{3}$ were used. The quartz glass substrates had been provided by CrysTec. $\mathrm{Al}_{2} \mathrm{O}_{3}$ was deposited by an atomic layer deposition (ALD) in a home-made chamber at $200^{\circ} \mathrm{C}$ substrate temperature. The complete process is described elsewhere. ${ }^{43}$ In addition, $\mathrm{Al}_{2} \mathrm{O}_{3}$ incorporated in a bottom-gate stack of a multi-layer structure of $\mathrm{Al}_{2} \mathrm{O}_{3}$ and $\mathrm{TiO}_{2}$ by $\mathrm{ALD}(250 \mathrm{~nm})$ on sputter-deposited indium tin oxide (ITO, $160 \mathrm{~nm}$ ) was used as substrate. In the following, this substrate is referred to as ATO. The dielectric surface and the interface to ITO consist of $25 \mathrm{~nm}$ pure $\mathrm{Al}_{2} \mathrm{O}_{3}$. Planar Systems (now Beneq) provided these substrates, which are used for the fabrication of p-type oxide TFTs, as reported in the literature. ${ }^{5,12,44,45}$ $\mathrm{Bi}_{2} \mathrm{O}_{3}$ was reactively sputtered from a $2 \mathrm{in}$. metallic $\mathrm{Bi}$ target provided by Alineason Materials Technology at $15 \mathrm{~W}$ (RF, $1.52 \mathrm{~W} \mathrm{in.}{ }^{-2}$ ) without substrate heating. A gas flow ratio of $10 \%$ oxygen was maintained at $0.5 \mathrm{~Pa}$ total pressure. $\mathrm{Bi}_{2} \mathrm{O}_{3}$ is an interesting material due to its high dielectric constant of approximately 40 , which has been studied previously in the system. $^{46,47}$

XPS was performed in a Physical Electronics PHI 5700 multi-technique surface analysis unit, using monochromatic $\mathrm{Al} \mathrm{K} \alpha$ radiation with an energy of $1486.6 \mathrm{eV}$, a take-off angle (TOA) of $45^{\circ}$, and a pass energy of $5.85 \mathrm{eV}$, resulting in an overall energy resolution of less than $0.4 \mathrm{eV}$. The system is equipped with an electron flood gun for charge compensation. In situ measurements of conductance $G$ were realized by connecting a Keithley 6487 picoammeter/voltage source to the sample through two electrical feedthroughs installed on the XPS chamber. The substrate had been prepared with two sputter-deposited gold electrodes in planar geometry. The width $w$ and the length $l$ of the measured sample area were in the range of $6.5-8.3 \mathrm{~cm}$ and $1.2-1.3 \mathrm{~cm}$, respectively. The ohmic contact to both electrodes was confirmed by current-voltage sweeps. As the measured currents have been in the range of picoampere especially at low thickness, the conductance was determined by applying a constant voltage of $1 \mathrm{~V}$ until the current reached a steady state. Then, the voltage bias was set to zero and the current was read again until steady state was reached. The difference of both steadystate currents was used for calculation of the conductance. The amount of voltage was chosen as compromise between high signal-to-noise ratio of the measurement and little current stress on the thin film.

The in situ XPS and IV characterization was done on $\mathrm{Cu}_{2} \mathrm{O}$ films deposited onto plane quartz glass and onto quartz glass coated either with $25 \mathrm{~nm} \mathrm{Al}_{2} \mathrm{O}_{3}$ or $45 \mathrm{~nm} \mathrm{Bi}_{2} \mathrm{O}_{3}$. Furthermore, ATO was investigated in two runs. One of the ATO runs involved an additional cleaning step by heating the substrate in $0.5 \mathrm{~Pa}$ oxygen at $200^{\circ} \mathrm{C}$ for $2 \mathrm{~h}$ immediately before film deposition. Then, two substrates of ATO coated with additional $45 \mathrm{~nm} \mathrm{Bi}_{2} \mathrm{O}_{3}$ were studied in two separate runs. With respect to deposition parameters, both runs were identical.

The quartz substrate showed rather pronounced charging during XPS measurement, which was partially compensated by the electron flood gun. For the analysis of the films on quartz glass coated with $\mathrm{Al}_{2} \mathrm{O}_{3}$ and $\mathrm{Bi}_{2} \mathrm{O}_{3}$, a second quartz substrate was sputter-coated with an additional gold layer 
prior to the respective deposition of $\mathrm{Al}_{2} \mathrm{O}_{3}$ and $\mathrm{Bi}_{2} \mathrm{O}_{3}$, which was added on the same sample holder next to the insulating substrate. While the insulating substrate served for conductance measurement, the conductive substrate was used for XPS analysis. In this way, the use of the electron flood gun could be avoided. The ATO substrates were subjected to less pronounced charging, so they did not require the use of charge compensation to obtain the spectra, however disregarding binding energies. In any case, charging disappeared as soon as a sufficiently thick $\mathrm{Cu}_{2} \mathrm{O}$ film had been deposited.

An Asylum Research MFP-3D atomic force microscope (AFM) was used to obtain surface roughnesses and average grain sizes at the surface, as well as current maps in contact mode with a voltage of $2 \mathrm{~V}$ applied to the tip (Asylum Research PPP-CONTPt). Scanning electron microscopy (SEM) was done with a Carl Zeiss Auriga. To obtain crosssectional images of the films, the samples had been manually broken prior to measurement. The Hall effect was measured with a custom Hall effect system ${ }^{48}$ as well as with a commercial BioRad HL5550. X-ray diffraction (XRD) measurements were done with a PANalytical X'Pert Pro Diffractometer in Bragg-Brentano geometry. Film thickness was measured by profilometry and the deposition rate was assumed to be independent on film thickness.

\section{RESULTS}

\section{A. Electrical film properties}

The different types of insulating substrates investigated in this study are referred to by the names as shown in Table I. Stoichiometry, Fermi energy and in situ conductivity $\sigma$ from planar geometry of thick $\mathrm{Cu}_{2} \mathrm{O}$ and $\mathrm{CuO}$ are reported. The conductivity is calculated according to Equation (2), where $Y$ is the reduced conductance, corrected for the electrode geometry

$$
\sigma=\frac{l}{w} \frac{G}{d}=\frac{Y}{d} .
$$

The film thickness of the samples listed in Table I was generally $254 \mathrm{~nm}$, except for sample ATO (1) (42 nm) and for $\mathrm{CuO}$ on ATO $(366 \mathrm{~nm})$. All surfaces of thick $\mathrm{Cu}_{2} \mathrm{O}$ films are stoichiometric within an error of 5\%. Accordingly, they were free of the characteristic spectral features described in Sec. II, which indicates the absence of $\mathrm{Cu}(0)$ and $\mathrm{Cu}(\mathrm{II})$. However, the conductivities at $254 \mathrm{~nm}$ film thickness are

TABLE I. Stoichiometry, Fermi energy, and conductivity (estimated from planar geometry).

\begin{tabular}{|c|c|c|c|}
\hline Substrate & Ratio $\mathrm{Cu} / \mathrm{O}$ & $E_{\mathrm{F}}-E_{\mathrm{VB}}(\mathrm{eV})$ & $\sigma\left(\mathrm{S} \mathrm{cm}^{-1} \times 10^{-3}\right)$ \\
\hline Quartz (q) & 1.98 & 0.26 & 0.3 \\
\hline $\mathrm{q} / \mathrm{Al}_{2} \mathrm{O}_{3}$ & 2.13 & 0.23 & 2.2 \\
\hline $\mathrm{q} / \mathrm{Bi}_{2} \mathrm{O}_{3}$ & 1.93 & 0.24 & 4.4 \\
\hline $\operatorname{ATO}(1)$ & 1.89 & 0.27 & 10.2 \\
\hline $\operatorname{ATO}(2)$ & 1.99 & 0.33 & 3.4 \\
\hline $\mathrm{ATO} / \mathrm{Bi}_{2} \mathrm{O}_{3}(1)$ & 2.05 & 0.29 & 8.6 \\
\hline $\mathrm{ATO} / \mathrm{Bi}_{2} \mathrm{O}_{3}(2)$ & 2.05 & 0.28 & 15.3 \\
\hline $\mathrm{CuO}$ on $\mathrm{ATO}$ & 0.86 & 0.06 & 166.6 \\
\hline
\end{tabular}

quite different according to the type of substrate. $\mathrm{Cu}_{2} \mathrm{O}$ on quartz shows the lowest value, followed by the $\mathrm{Al}_{2} \mathrm{O}_{3}$ substrates. The low conductivity on quartz is not due to a measurement artifact, since a similarly low value was obtained on a sapphire substrate (not shown here). The highest conductivities in $\mathrm{Cu}_{2} \mathrm{O}$ are obtained on $\mathrm{Bi}_{2} \mathrm{O}_{3}$ with further increase when deposited on $\mathrm{ATO} / \mathrm{Bi}_{2} \mathrm{O}_{3}$. In $\mathrm{CuO}$, the conductivity is comparatively high in accordance with the low Fermi energy. The remainder of this article is concerned with the wide range of conductivities observed in $\mathrm{Cu}_{2} \mathrm{O}$ by evaluating the data with respect to film thickness.

Figure 1 shows the change in reduced conductance with an increasing copper oxide thickness on a linear scale and in double-logarithmic representation. The value of $Y$ before any film deposition is at least five orders of magnitude lower than the final reduced conductance for all experiments. As the measurements were performed in the vacuum system directly after deposition, this observation is related to the film properties and not to an extrinsic surface effect, which may be caused, for example, by adsorbates. The most striking observation from Figs. 1(a)-1(c) is the strong initial increase of conductance at thicknesses below $10 \mathrm{~nm}$, compared to the slope at higher thicknesses. This is found both for $\mathrm{Cu}_{2} \mathrm{O}$ and $\mathrm{CuO}$. Figs. 1(d) and 1(e) reveal the different thicknesses, at which the onset of conduction occurs. The root mean square (RMS) roughness of ATO-based substrates is about $5 \mathrm{~nm}$, which explains the observed higher conduction onset thickness compared to $\mathrm{q} / \mathrm{Al}_{2} \mathrm{O}_{3}$ and $\mathrm{q} / \mathrm{Bi}_{2} \mathrm{O}_{3}$. The quartz-based substrates have a similar RMS roughness of $0.4 \mathrm{~nm}$. The reason for the relatively high onset thickness on quartz compared to $\mathrm{q} / \mathrm{Al}_{2} \mathrm{O}_{3}$ and $\mathrm{q} / \mathrm{Bi}_{2} \mathrm{O}_{3}$ is therefore supposed to be related to a different substrate-film interaction. In Figure 1(f), it is noteworthy, that for thicknesses below $5 \mathrm{~nm}$, the conductance of $\mathrm{Cu}_{2} \mathrm{O}$ is nearly identical to $\mathrm{CuO}$.

\section{B. XPS analysis}

Depending on film thickness, systematic changes in $\mathrm{Cu}$ $2 \mathrm{p}_{3 / 2}$ satellite intensity from the $\mathrm{Cu}_{2} \mathrm{O}$ films could be identified by XPS. Figure 2 shows the $\mathrm{Cu} 2 \mathrm{p}_{3 / 2}$ spectra of all $\mathrm{Cu}_{2} \mathrm{O}$ thicknesses on $\mathrm{q} / \mathrm{Al}_{2} \mathrm{O}_{3}$ as representative example. In order to obtain a semi-quantification of the relative amount of satellite emission with respect to film thickness, the following procedure was applied to each experiment: The background was removed according to the method of Shirley in the binding energy range of $\mathrm{Cu} 2 \mathrm{p}_{3 / 2}$ including the satellite region (around $927 \mathrm{eV}-948.5 \mathrm{eV}$ ). Then, the areal intensity of this region was calculated, and the spectra were normalized to the respective area. The difference between the spectra of each thickness and of the final film was then calculated and integrated in the region, where $\mathrm{Cu} 2 \mathrm{p}_{3 / 2}$ satellites typically appear (around $938.3 \mathrm{eV}-945.8 \mathrm{eV}$ ). The relative satellite sensitivity of $\mathrm{Cu}_{2} \mathrm{O}$ is zero by definition and around 0.3 , when calculated for $\mathrm{CuO}$.

The relative intensity of the $\mathrm{Cu} 2 \mathrm{p}_{3 / 2}$ satellite emission with respect to the main line intensity is plotted against $\mathrm{Cu}_{2} \mathrm{O}$ film thickness in Figure 3(a). In order to compare the data to the conductance results, the conductivity $\sigma$ is shown in Figure 3(b). A general accordance of $\mathrm{Cu}$ (II) satellite 

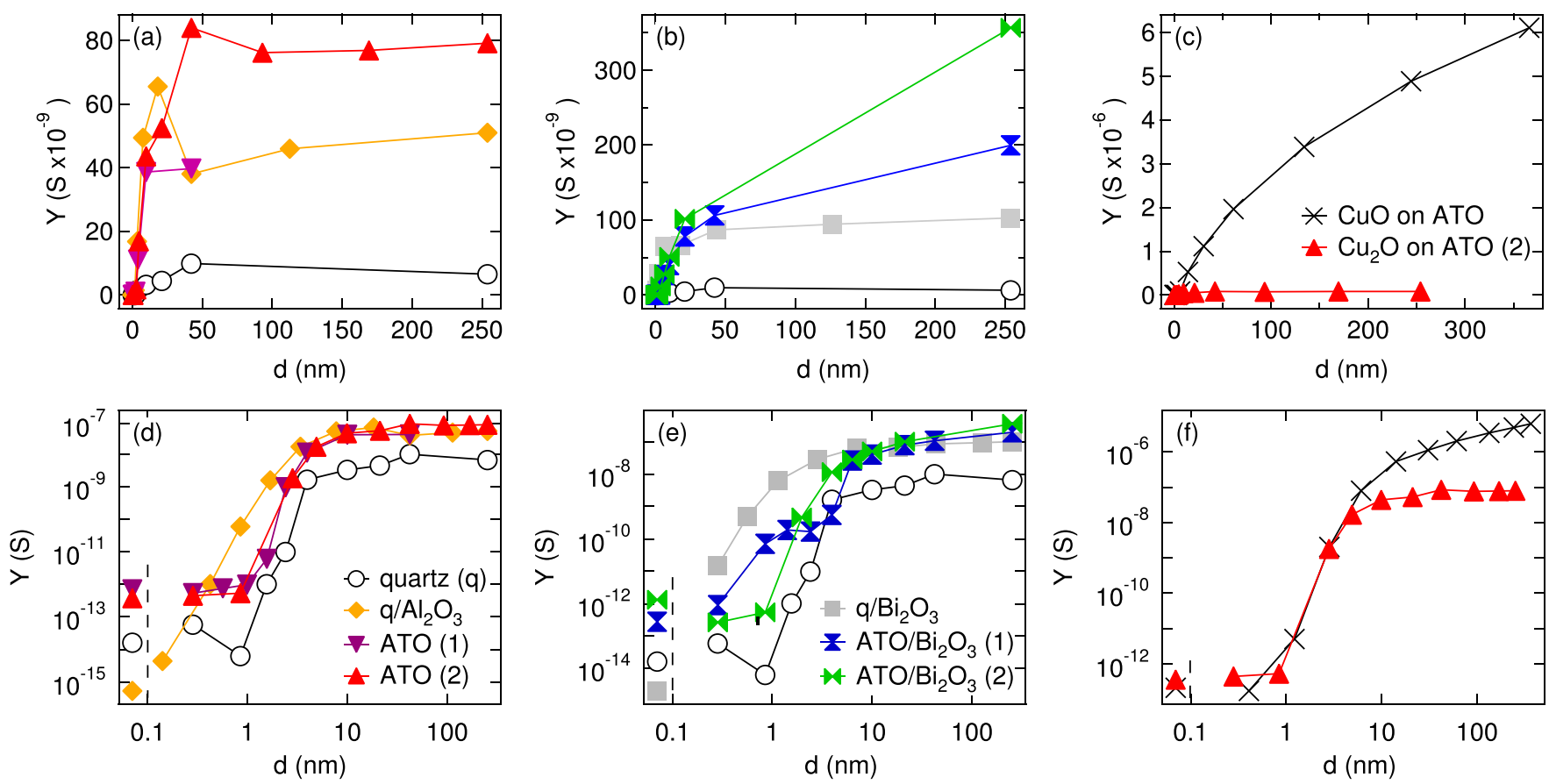

FIG. 1. In situ reduced conductance data are shown with respect to increasing copper oxide thickness (a)-(c) on linear and (d)-(f) on double-logarithmic scale.

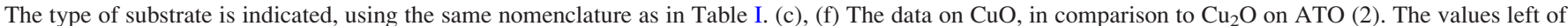
the broken line correspond to the uncoated substrate (at arbitrary thickness).

intensity and conductivity is apparent. However, the maximum satellite intensity is generally observed at lower thicknesses than the maximum conductivity. Note that the substrate ATO (1) had been heated at $200^{\circ} \mathrm{C}$ in $0.5 \mathrm{~Pa}$ oxygen for $2 \mathrm{~h}$ prior to film deposition. This additional surface cleaning step may be the reason for the lower satellite intensity compared to that of $\mathrm{Cu}_{2} \mathrm{O}$ on ATO (2). However, this does not affect the film conductivity, which is similar for both samples.

\section{Morphology}

There is obviously a relationship between the excess conductivity and the $\mathrm{Cu}(\mathrm{II})$-related satellite intensity,

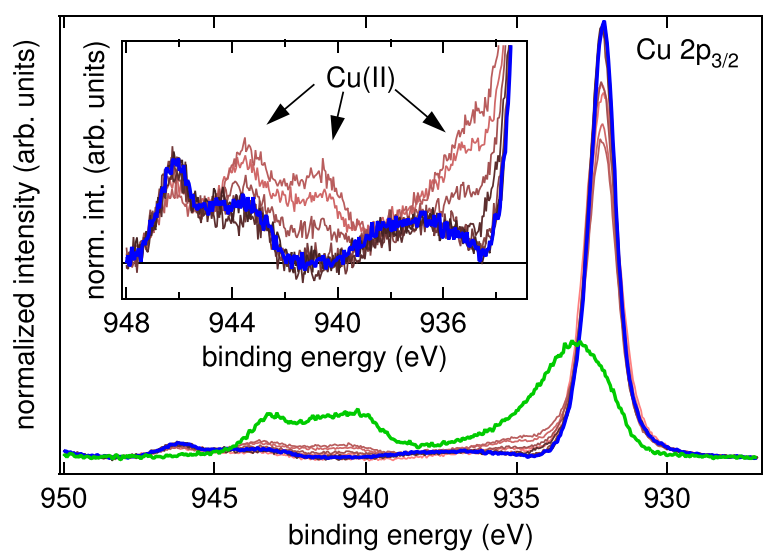

FIG. 2. Spectra of the $\mathrm{Cu} 2 \mathrm{p}_{3 / 2}$ satellite region of copper oxide on $\mathrm{q} / \mathrm{Al}_{2} \mathrm{O}_{3}$ are shown as example to illustrate the thickness-dependent amount of $\mathrm{Cu}$ (II) satellite emission and the procedure for semi-quantification. The blue curve is the spectrum after the final deposition step, which is supposed to represent pure $\mathrm{Cu}_{2} \mathrm{O}$. The dark brown to light brown curves are the spectra at intermediate thicknesses. The green curve represents data of $\mathrm{CuO}$. observed at low and intermediate $\mathrm{Cu}_{2} \mathrm{O}$ thicknesses. In order to investigate whether grain boundaries have an effect on conductivity, the morphology of $\mathrm{Cu}_{2} \mathrm{O}$ is included into the analysis. XRD has shown the material to be of
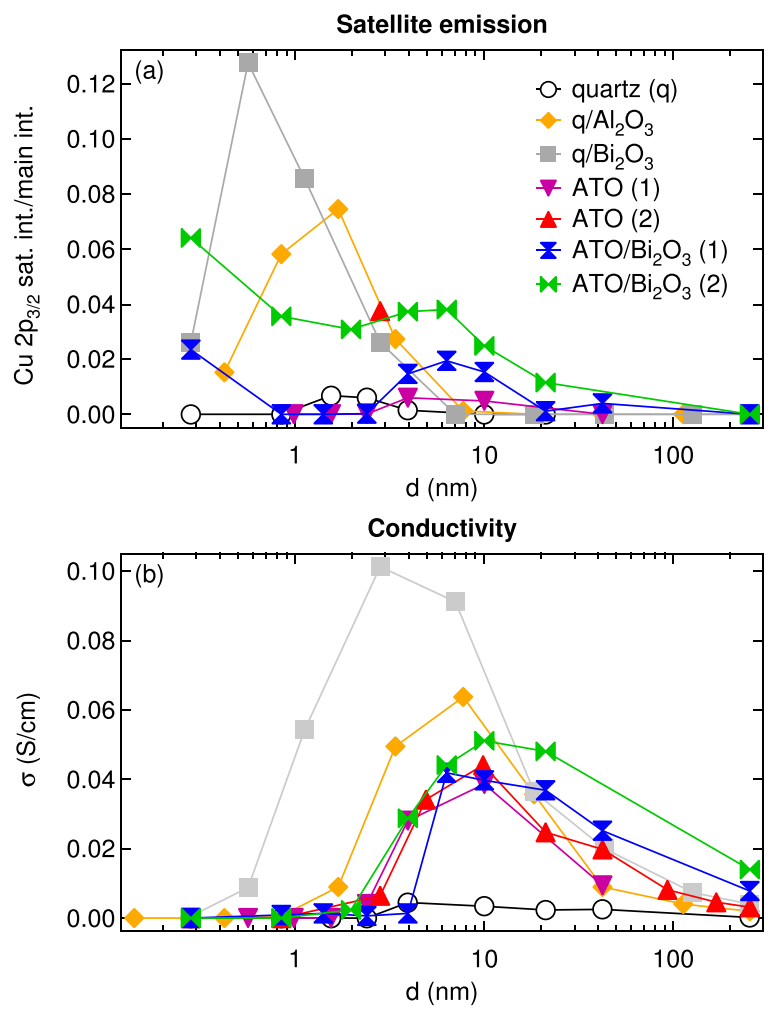

FIG. 3. (a) The relative amount of $\mathrm{Cu} 2 \mathrm{p}_{3 / 2}$ satellite emission is displayed with respect to $\mathrm{Cu}_{2} \mathrm{O}$ film thickness. XPS data of intermediate film thicknesses on ATO (2) has been acquired only at a thickness of $2.8 \mathrm{~nm}$. (b) Conductivity with respect to $\mathrm{Cu}_{2} \mathrm{O}$ thickness as calculated from reduced conductance data. 


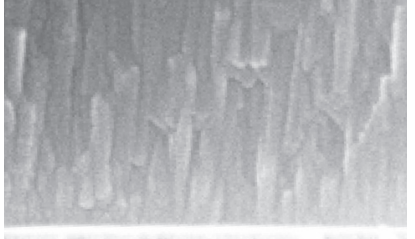

(a)

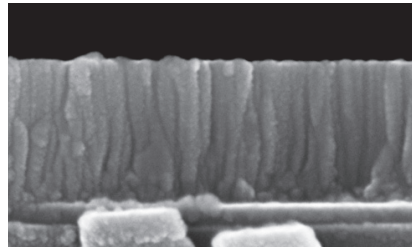

(b)

FIG. 4. Cross-sectional SEM images of $\mathrm{Cu}_{2} \mathrm{O}$ (a) on corning glass and (b) on $\mathrm{q} / \mathrm{Al}_{2} \mathrm{O}_{3}$.

polycrystalline cuprite phase without preferential crystallographic orientation, similar to the previous work. ${ }^{37}$ No $\mathrm{CuO}$ phase could be detected by XRD (not shown here). Crosssectional SEM images of $\mathrm{Cu}_{2} \mathrm{O}$ on corning glass and $\mathrm{q} / \mathrm{Al}_{2} \mathrm{O}_{3}$ are displayed in Figure 4. A fibrous grain structure is found, with a lateral grain size which increases with thickness. ${ }^{3}$ AFM topographies have been used to obtain a rough estimate of the grain size at the surface after complete film deposition. An average value of $35 \pm 15 \mathrm{~nm}$ was obtained, without systematic dependency on the substrate material.

Conductive atomic force microscopy (CAFM) was measured to obtain direct evidence for an increased grain boundary conductivity. The best results were obtained on a $100 \mathrm{~nm}$ thick sample deposited on ITO-coated glass in a commercial stand-alone sputtering chamber by AJA International. On these samples, $\mathrm{Cu}_{2} \mathrm{O}$ phase purity without preferential crystallographic orientation was confirmed by XRD and optical transmittance spectroscopy (not shown here). Topography and current map are presented in Figure 5. The thin bright lines of increased current between the grains are clear evidence for the increased grain boundary conductivity.

\section{DISCUSSION}

When the lateral grain size $L$ increases with thickness according to Equation (1), the volume fraction of grain boundaries decreases with increasing thickness. Consequently, if a grain boundary effect is at play, enhanced conductance at low thicknesses can only be explained by the existence of more conductive grain boundaries with respect to the grain interior. Göbel et al. have described the increase in grain boundary conductance for the columnar morphology of their samples by a model of cuboid grains of horizontal dimensions $L$ and a vertical extension equal to the film thickness $d{ }^{49}$ Grain boundaries perpendicular to the current flow are

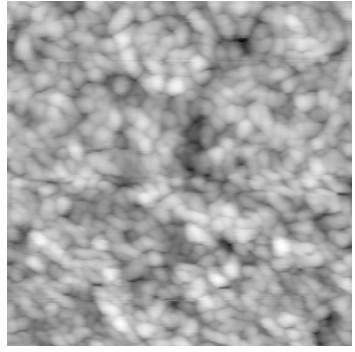

(a) (b)

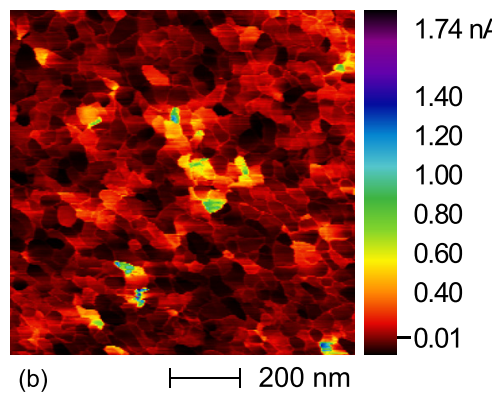

FIG. 5. (a) Topography and (b) current map of $\mathrm{Cu}_{2} \mathrm{O}$ on ITO-coated glass. neglected. The total reduced conductance $Y$ with respect to thickness is expressed as parallel connection of grain conductance $Y_{\text {grain }}$ and grain boundary conductance $Y_{\mathrm{GB}}$

$$
Y=Y_{\text {grain }}+Y_{\mathrm{GB}}
$$

The situation is illustrated in Figure 6(a). Figure 6(b) shows a schematic representation of a film morphology with linear cone faces $(n=1)$. Upon an increase in average grain size $L$ with $d$, regions close to the substrate interface remain at smaller $L$ than regions close to the film surface. For this reason, the total conductance needs to be integrated over thickness

$$
Y(d)=\int_{0}^{d} \sigma^{*}(z) \mathrm{d}(z) .
$$

When dividing $Y(d)$ by the film thickness $d$ according to Equation (2), an average value for conductivity of the inhomogeneous thin film is obtained. An expression for $\sigma^{*}(z)$, which satisfies the interpretation by Göbel et al., is given in the following equation:

$$
\sigma^{*}(z)=\sigma_{\text {grain }} \frac{L(z)}{L(z)+W}+\sigma_{\mathrm{GB}} \frac{W}{L(z)+W},
$$

$\sigma_{\mathrm{GB}}$ and $\sigma_{\text {grain }}$ are the respective conductivities of grain boundary and grain. The grain boundary width $W$ is below a nanometer, since it describes a rather highly doped region. ${ }^{49}$ Figures 7(a) and 7(b) show results from the model, calculated with $W=0.5 \mathrm{~nm}$. In the calculation, the grains begin to grow laterally only at a thickness of $1 \mathrm{~nm}$, which is supposed to account for an interface layer of high conductivity, equal to $\sigma_{\mathrm{GB}}$. The conductivity inside the grains is chosen equal to monocrystalline $\mathrm{Cu}_{2} \mathrm{O}$ and the grain boundary conductivity is within the range of typical values for $\mathrm{CuO}\left(0.01 \mathrm{~S} \mathrm{~cm}^{-1}\right.$ as single crystal and $1 \mathrm{~S} \mathrm{~cm}^{-1}$ as thin film, sputtered-deposited at room temperature). ${ }^{25,26,30}$ All curves have been calculated with $\sigma_{\text {grain }}=10^{-6} \mathrm{~S} / \mathrm{cm}$ and $\sigma_{\mathrm{GB}}=0.1 \mathrm{~S} / \mathrm{cm}$. For comparison, Fig. 7(c) reproduces the measured conductivities on the same scale. Due to the limited amount of data points at different thicknesses for each substrate material, a reliable fitting of the data could not be conducted.

Fig. 7(a) illustrates the effect of different $L(z)$ on the calculated conductivity. Apart from of the linear relation $(n=1)$, a square dependency $(n=2)$ in red and a cubic one $(n=3)$ in gray are displayed. The more drastic the initial increase in $L$, the stronger is the conductivity decay with (a)

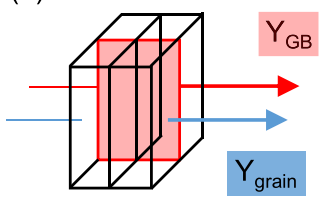

(b)

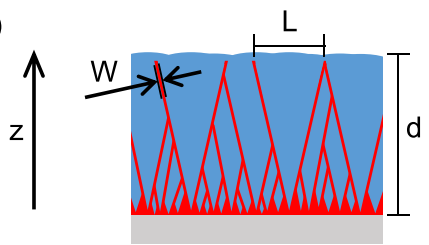

FIG. 6. (a) The two parallel currents through the grain boundary (red) and through the grains (blue) are illustrated, together with the respective conductances. (b) Schematic representation of the film morphology, where $L$ is the grain size, $W$ is the width of the grain boundary, and $d$ is the film thickness along $z$. 

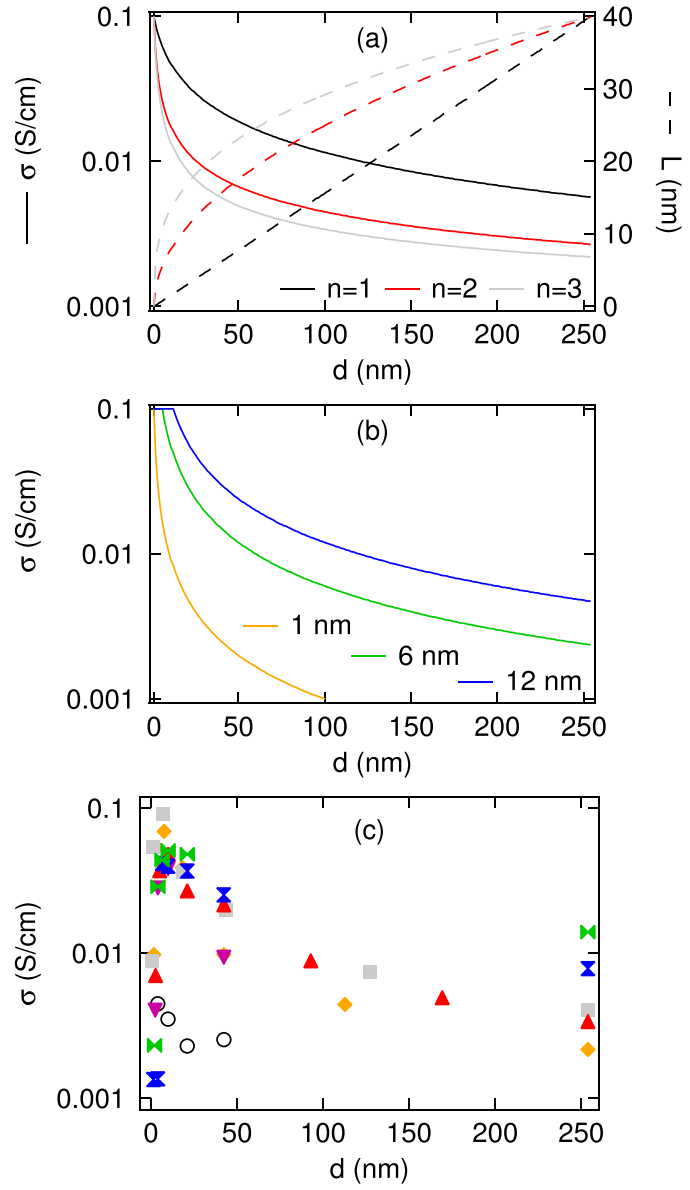

FIG. 7. Effective conductivity from calculation for different (a) grain growth models $L(z)$ and (b) interface layer thicknesses. The final grain size of $L=40 \mathrm{~nm}$ is similar to the experimentally obtained values. (c) Conductivities from the experiment are shown with the same symbol coding as in Figs. 1 and 3.

increasing thickness. Fig. 7(b) shows that a similar change in $\sigma$ can be obtained by considering an interface layer with conductivity equal to $\sigma_{\mathrm{GB}}$ and a monocrystalline bulk material of $\sigma_{\text {grain }}$.

It is apparent from Figure 7 that thickness-dependent analysis of conductance alone cannot distinguish whether an enhanced conductivity at low thickness is due to an interface or a grain boundary effect. ${ }^{49}$ For this reason, additional experimental evidence needs to be considered. In the previous study, conductivity measurements on $\mathrm{CuO}$ thin films of different grain sizes with respect to temperature and atmosphere revealed the existence of more conductive grain boundaries in this material. ${ }^{30}$ In the light of the present discussion, this corresponds well to the initially enhanced conductivity in $\mathrm{CuO}$ displayed in Figures 1(c) and 1(f). For bulk samples of $\mathrm{Cu}_{2} \mathrm{O}$, there is evidence in the literature to support the idea of the increased grain boundary conductivity. ${ }^{22,23}$ The Hall effect measurements on $\mathrm{Cu}_{2} \mathrm{O}$ thin films by Lee et al. confirm this, although not discussed by the authors: As the average grain size is reduced by two orders of magnitude, (1) carrier concentration increases while mobility decreases up to the point that no stable Hall voltage is obtained. Simultaneously, (2) the concentration of ionized impurities increases, which dominate charge carrier scattering at low temperature. ${ }^{3}$ An increasing impurity concentration gradually changes the electrical properties of $\mathrm{Cu}_{2} \mathrm{O}$ to be rather similar to $\mathrm{CuO}$. Given the possibility of highly conductive grain boundaries, a segregation of defects in the grain boundary can correlate observation (1) with observation (2). Consequently, grain boundaries are concluded to be the cause for the increased conductivity at low film thickness, as presented in this article. The results presented here show that XPS is able to detect the relevant change in cation oxidation state to prove the existence of $\mathrm{Cu}$ (II). The increased $\mathrm{Cu}$ (II)-related intensity at low film thickness where grain size is expected to be relatively small suggests that $\mathrm{Cu}$ (II) is present at the grain boundaries of $\mathrm{Cu}_{2} \mathrm{O}$. It is important for this assignment that the analysis is carried out in dependence on thickness, non-destructively, and in vacuum, which prevents surface oxidation.

The $\mathrm{Cu}_{2} \mathrm{O}$ films are apparently rich in oxygen at low thickness, despite no sign for non-stoichiometry at high thickness (see Table I). Under more reducing deposition conditions, the formation of $\mathrm{Cu}(0)$ becomes more likely. The width of the depletion layer, caused by the $\mathrm{Cu} / \mathrm{Cu}_{2} \mathrm{O}$ Schottky junction is $0.5-1 \mu \mathrm{m} .{ }^{24}$ In case $\mathrm{Cu}(0)$ segregates in the grain boundaries, grains of similar size as in the present study would be fully depleted and no thickness dependence of conductivity could be observed by the here applied experimental procedure.

Given that $\mathrm{Cu}$ (II) is present at the grain boundaries in $\mathrm{Cu}_{2} \mathrm{O}$ thin films, the film may be approximated by $\mathrm{Cu}_{2} \mathrm{O}$ grains separated by $\mathrm{CuO}$ grain boundary phases. Transmission electron microscopy could confirm the existence of a $\mathrm{CuO}$ phase between $\mathrm{Cu}_{2} \mathrm{O}$ grains, however an in situ sample preparation procedure would be required to prevent additional oxidation by exposure to ambient air, which was not available. In case any $\mathrm{CuO}$ phase is formed, the interface between $\mathrm{Cu}_{2} \mathrm{O}$ and $\mathrm{CuO}$ is important for determining the grain boundary properties. As a direct determination of the energy band alignment between $\mathrm{Cu}_{2} \mathrm{O}$ and $\mathrm{CuO}$ is not possible using photoemission, the corresponding alignment is derived here using the transitivity rule according to $\Delta E_{\mathrm{VB}}$ $\left(\mathrm{Cu}_{2} \mathrm{O}, \mathrm{CuO}\right)=\Phi_{\mathrm{B}}\left(\mathrm{Cu}_{2} \mathrm{O}, \mathrm{M}\right)+\Phi_{\mathrm{B}}(\mathrm{M}, \mathrm{CuO}) . \Phi_{\mathrm{B}}$ is the Schottky barrier for holes at the corresponding interface. $M$ represents a common metal. This procedure has been successfully applied to interfaces of semiconducting oxides. ${ }^{50,51}$ Figure 8(a) schematically shows Fermi energies in $\mathrm{Cu}_{2} \mathrm{O}$ and $\mathrm{CuO}$ at the contacts to $\mathrm{RuO}_{2}$, ITO, and Au. The data have been obtained by photoemission according to the method by Kraut $e t a l .{ }^{52}$ and are partially taken from the previous studies. ${ }^{30,37,53}$ The valence band discontinuity between $\mathrm{CuO}$ and $\mathrm{Cu}_{2} \mathrm{O}$ is $0.2 \mathrm{eV}$. In the case of a grain boundary segregation of $\mathrm{CuO}$ in $\mathrm{Cu}_{2} \mathrm{O}$, a schematic energy band alignment as sketched in Figure 8(b) will occur. The higher valence band maximum at the grain boundaries immediately explains the higher carrier concentration and therefore the higher conductivity of the grain boundary.

\section{CONCLUSION}

The analysis of conductance with respect to film thickness in UHV conditions has shown increased conductivity in polycrystalline $\mathrm{Cu}_{2} \mathrm{O}$ thin films at low thicknesses. By 


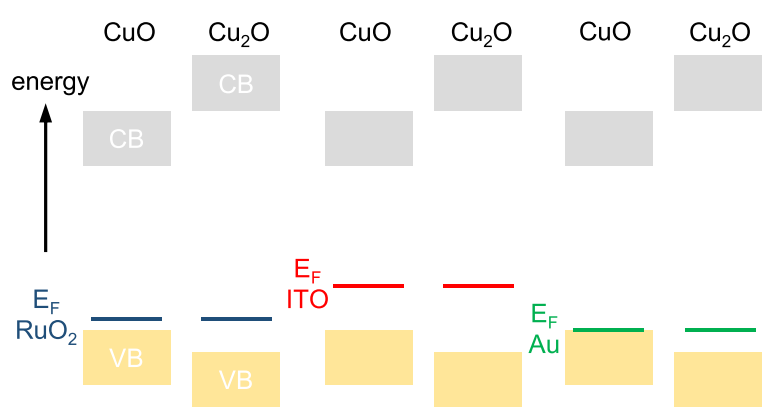

(a)

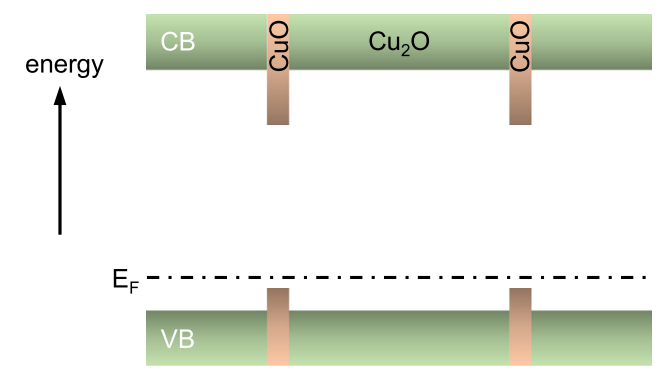

(b)

FIG. 8. (a) Fermi energies in the band gap of $\mathrm{CuO}$ and $\mathrm{Cu}_{2} \mathrm{O}$ at the contact to different metals. Valence band and conduction band are designated as VB and $\mathrm{CB}$, respectively. (b) Schematic energy band alignment between grains of $\mathrm{Cu}_{2} \mathrm{O}$ and grain boundaries of segregated $\mathrm{CuO}$.

simultaneous XPS measurement, this could be related to the occurrence of $\mathrm{Cu}(\mathrm{II})$, giving rise to a rather oxygen-rich region at low thickness, even in case of ideal stoichiometry at the surface of the final film. These extrinsic defects are likely to segregate to the grain boundaries, causing the electrical properties of the same to be similar to $\mathrm{CuO}$ and masking the low carrier concentration and high hole mobility of $\mathrm{Cu}_{2} \mathrm{O}$ thin films. As grains grow with increasing thickness, the strongest conductivity enhancement occurs at the interface to the substrate. Additional effects at the interface also have to be considered, as they cannot be ruled out by this method. One requirement for fabrication of low-cost transparent electronics is a thin p-type semiconducting oxide, deposited at low temperature. The presented results provide an explanation for widely encountered difficulties in achieving this with $\mathrm{Cu}_{2} \mathrm{O}$. The high conductance of grain boundaries might also be responsible for the low conversion efficiencies of solar cells prepared from $\mathrm{Cu}_{2} \mathrm{O}$ thin films.

\section{ACKNOWLEDGMENTS}

The authors would like to acknowledge Daniela Nunes for the SEM measurements. This work is funded by FEDER funds through the COMPETE 2020 program and national funds through FCT-Portuguese Foundation for Science and Technology under the Project No. POCI-01-0145-FEDER007688, reference UID/CTM/50025 as well as SFRH/BD/ 77103/2011, UID/CTM/50025/2013, PEst-C/CTM/LA0025/ 2013-14, and EXCL/CTM-NAN/0201/2012. Furthermore, it has been supported by the German Science Foundation within the collaborative research center SFB 595 (Electrical Fatigue of Functional Material).
${ }^{1}$ E. Fortunato, P. Barquinha, and R. Martins, Adv. Mater. 24, 2945 (2012).

${ }^{2}$ S. Nikitine, J. Grun, and M. Sieskind, J. Phys. Chem. Solids 17, 292 (1961).

${ }^{3}$ Y. S. Lee, M. T. Winkler, S. C. Siah, R. Brandt, and T. Buonassisi, Appl. Phys. Lett. 98, 192115 (2011).

${ }^{4}$ H. Al-Jawhari, Mater. Sci. Semicond. Process. 40, 241 (2015).

${ }^{5}$ E. Fortunato, V. Figueiredo, P. Barquinha, E. Elamurugu, R. Barros, G. Gonçalves, S.-H. K. Park, C.-S. Hwang, and R. Martins, Appl. Phys. Lett. 96, 192102 (2010).

${ }^{6}$ V. Figueiredo, E. Elangovan, R. Barros, J. V. Pinto, T. Busani, R. Martins, and E. Fortunato, J. Disp. Technol. 8, 41 (2012).

${ }^{7}$ X. Zou, G. Fang, L. Yuan, M. Li, W. Guan, and X. Zhao, IEEE Electron Device Lett. 31, 827 (2010).

${ }^{8}$ S.-Y. Sung, S.-Y. Kim, K.-M. Jo, J.-H. Lee, J.-J. Kim, S.-G. Kim, K.-H. Chai, S. J. Pearton, D. P. Norton, and Y.-W. Heo, Appl. Phys. Lett. 97, 222109 (2010).

${ }^{9}$ D.-W. Nam, I.-T. Cho, J.-H. Lee, E.-S. Cho, J. Sohn, S.-H. Song, and H.-I. Kwon, J. Vac. Sci. Technol., B 30, 060605 (2012).

${ }^{10}$ C.-Y. Jeong, J. Sohn, S.-H. Song, I.-T. Cho, J.-H. Lee, E.-S. Cho, and H.-I. Kwon, Appl. Phys. Lett. 102, 082103 (2013).

${ }^{11}$ Z. Q. Yao, S. L. Liu, L. Zhang, B. He, A. Kumar, X. Jiang, W. J. Zhang, and G. Shao, Appl. Phys. Lett. 101, 042114 (2012).

${ }^{12} \mathrm{H}$. Al-Jawhari and J. Caraveo-Frescsa, Adv. Mater. Res. 856, 215 (2013).

${ }^{13}$ K. Matsuzaki, K. Nomura, H. Yanagi, T. Kamiya, M. Hirano, and H. Hosono, Appl. Phys. Lett. 93, 202107 (2008).

${ }^{14}$ K. Matsuzaki, K. Nomura, H. Yanagi, T. Kamiya, M. Hirano, and H. Hosono, Phys. Status Solidi A 206, 2192 (2009).

${ }^{15}$ A. Rosencwaig and G. Wertheim, J. Electron Spectrosc. Relat. Phenom. 1, 493 (1972).

${ }^{16}$ F.-Y. Ran, H. Hiramatsu, H. Hosono, T. Kamiya, and M. Taniguti, J. Vac. Sci. Technol., B 33, 051211 (2015).

${ }^{17}$ F.-Y. Ran, M. Taniguti, H. Hosono, and T. Kamiya, J. Disp. Technol. 11, 720 (2015).

${ }^{18}$ J. Xue and R. Dieckmann, J. Phys. Chem. Solids 51, 1263 (1990).

${ }^{19}$ O. Porat and I. Riess, Solid State Ionics 74, 229 (1994).

${ }^{20}$ M. Martinez-Clemente and R. D. Schmidt-Whitley, J. Mater. Sci. 10, 543 (1975).

${ }^{21}$ B. K. Moss, P. Goodman, and A. W. S. Johnson, J. Solid State Chem. 73, 268 (1988).

${ }^{22}$ F. L. Weichman, J. Appl. Phys. 41, 3491 (1970).

${ }^{23}$ S. Aggarwal, Solid State Ionics 101-103, 321 (1997).

${ }^{24}$ W. H. Brattain, Rev. Mod. Phys. 23, 203 (1951).

${ }^{25}$ E. Fortin and F. L. Weichman, Can. J. Phys. 44, 1551 (1966).

${ }^{26}$ A. A. Samokhvalov, N. A. Viglin, B. A. Gizhevskij, N. N. Loshkareva, V. V. Osipov, N. I. Solin, and Y. P. Sukhorukov, Zh. Eksp. Teor. Fiz. 103, 951 (1993).

${ }^{27}$ B. K. Meyer, A. Polity, D. Reppin, M. Becker, P. Hering, P. J. Klar, T. Sander, C. Reindl, J. Benz, M. Eickhoff, C. Heiliger, M. Heinemann, J. Bläsing, A. Krost, S. Shokovets, C. Müller, and C. Ronning, Phys. Status Solidi B 249, 1487 (2012).

${ }^{28}$ J. Ghijsen, L. H. Tjeng, J. van Elp, H. Eskes, J. Westerink, G. A. Sawatzky, and M. T. Czyzyk, Phys. Rev. B 38, 11322 (1988).

${ }^{29} \mathrm{C}$. Benndorf, H. Caus, B. Egert, H. Seidel, and F. Thieme, J. Electron Spectrosc. Relat. Phenom. 19, 77 (1980).

${ }^{30}$ J. Morasch, H. F. Wardenga, W. Jaegermann, and A. Klein, "Influence of grain boundaries and interfaces on the electronic structure of polycrystalline $\mathrm{CuO}$ thin films," Phys. Status Solidi A (published online).

${ }^{31}$ B. A. Movchan and A. V. Demchishim, Phys. Met. Metallogr. 28, 83 (1969).

${ }^{32}$ R. Messier, J. Vac. Sci. Technol., A 4, 490 (1986).

${ }^{33}$ J. W. Orton and M. J. Powell, Rep. Prog. Phys. 43, 1263 (1980).

${ }^{34}$ J. Volger, Phys. Rev. 79, 1023 (1950).

${ }^{35}$ J. Y. W. Seto, J. Appl. Phys. 46, 5247 (1975).

${ }^{36}$ A. Klein, J. Am. Ceram. Soc. 96, 331 (2013).

${ }^{37}$ J. Deuermeier, J. Gassmann, J. Brötz, and A. Klein, J. Appl. Phys. 109, 113704 (2011).

${ }^{38}$ J. F. Moulder, W. F. Stickle, P. E. Sobol, and K. D. Bomben, Handbook of $X$-Ray Photoelectron Spectroscopy (Physical Electronics, Inc., Eden Prairie, 1995).

${ }^{39}$ D. Frost, A. Ishitani, and C. McDowell, Mol. Phys. 24, 861 (1972).

${ }^{40}$ P. E. Larson, J. Electron Spectrosc. Relat. Phenom. 4, 213 (1974).

${ }^{41}$ F. L. Weichman, Can. J. Phys. 60, 269 (1982).

${ }^{42}$ J. Deuermeier, T. J. M. Bayer, H. Yanagi, A. Kiazadeh, R. Martins, A. Klein, and E. Fortunato, Mater. Res. Express 3, 046404 (2016). 
${ }^{43}$ T. J. M. Bayer, A. Wachau, A. Fuchs, J. Deuermeier, and A. Klein, Chem. Mater. 24, 4503 (2012).

${ }^{44}$ E. Fortunato, V. Figueiredo, P. Barquinha, E. Elamurugu, R. Barros, G. Gonçalves, S.-H. K. Park, C.-S. Hwang, and R. Martins, Appl. Phys. Lett. 96, 239902 (2010).

${ }^{45}$ Z. Wang, H. A. Al-Jawhari, P. K. Nayak, J. A. Caraveo-Frescas, N. Wei, M. N. Hedhili, and H. N. Alshareef, Sci. Rep. 5, 9617 (2015).

${ }^{46}$ S. Li, J. Morasch, A. Klein, C. Chirila, L. Pintilie, L. Jia, K. Ellmer, M. Naderer, K. Reichmann, M. Gräting, and K. Albe, Phys. Rev. B 88 , 045428 (2013).

${ }^{47}$ J. Morasch, S. Li, J. Brötz, W. Jaegermann, and A. Klein, Physica Status Solidi A 211, 93 (2014).

${ }^{48}$ M. V. Hohmann, A. Wachau, and A. Klein, Solid State Ionics 262, 636 (2014).
${ }^{49}$ M. C. Göbel, G. Gregori, X. Guo, and J. Maier, Phys. Chem. Chem. Phys. 12, 14351 (2010).

${ }^{50}$ R. Schafranek, S. Li, F. Chen, W. Wu, and A. Klein, Phys. Rev. B 84, 045317 (2011).

${ }^{51}$ S. Li, F. Chen, R. Schafranek, T. J. M. Bayer, K. Rachut, A. Fuchs, S. Siol, M. Weidner, M. Hohmann, V. Pfeifer, J. Morasch, C. Ghinea, E. Arveux, R. Günzler, J. Gassmann, C. Körber, Y. Gassenbauer, F. Säuberlich, G. V. Rao, S. Payan, M. Maglione, C. Chirila, L. Pintilie, L. Jia, K. Ellmer, M. Naderer, K. Reichmann, U. Böttger, S. Schmelzer, R. C. Frunza, H. Ursic, B. Malic, W.-B. Wu, P. Erhart, and A. Klein, Phys. Status Solidi RRL 8, 571 (2014).

${ }^{52}$ J. R. Waldrop, W. Grant, S. P. Kowalczyk, and E. A. Kraut, J. Vac. Sci. Technol., A 3, 835 (1985).

${ }^{53}$ S. Siol, "Kupfer-Chalkogenide für photovoltaische Anwendungen," Ph.D. thesis, Technische Universität Darmstadt, 2014.

This article may be downloaded for personal use only. Any other use requires prior permission of the author and AIP Publishing. This article appeared in Journal of Applied Physics 119, 235303 (2016) and may be found at https://doi.org/10.1063/1.4954002.

Available under only the rights of use according to UrhG. 